\title{
The activation of proteinase-activated receptor-1 (PAR1) promotes gastric cancer cell alteration of cellular morphology related to cell motility and invasion
}

\author{
DAISUKE FUJIMOTO ${ }^{1}$, YASUO HIRONO ${ }^{1}$, TAKANORI GOI ${ }^{1}$, KANJI KATAYAMA ${ }^{1}$, \\ SHIGERU MATSUKAWA ${ }^{2}$ and AKIO YAMAGUCHI ${ }^{1}$ \\ ${ }^{1}$ First Department of Surgery, Faculty of Medicine and Division of Bioresearch Laboratories, \\ ${ }^{2}$ Centers for Advanced Research Support, University of Fukui, Fukui 910-1193, Japan
}

Received October 9, 2012; Accepted November 23, 2012

DOI: $10.3892 /$ ijo.2012.1738

\begin{abstract}
Cell motility proceeds by cycles of edge protrusion, adhesion and retraction. Whether these functions are coordinated by biochemical or biomechanical processes is unknown. Tumor invasion and metastasis is directly related to cell motility. We showed that stimulation of proteinase-activated receptor-1 (PAR1) can trigger an array of responses that would promote tumor cell growth and invasion. Thus, we examined aspects of PAR1 activation related to cell morphological change that might contribute to cell motility. We established a PAR1 stably transfected MKN45 gastric cancer cell line (MKN45/PAR1). We examined morphological changes, Rho family activation and overexpression of cytoskeletal protein in cells exposed to PAR1 agonists ( $\alpha$-thrombin and TFLLR-NH ${ }_{2}$ ). MKN45/PAR1 grows with an elongated and polarized morphology, extending pseudopodia at the leading edge. However, in the presence of PAR1 antagonist, MKN45/PAR1 did not show any changes in cell shape upon addition of either $\alpha$-thrombin or TFLLR-NH $\mathrm{N}_{2}$. Activated PAR1 induced RhoA and Racl phosphorylation, and subsequent overexpression of myosin IIA and filamin B which are stress fiber components that were identified by PMF analysis of peptide mass data obtained by MALDI-TOF/MS measurement. Upon stimulation of MKN45/PAR1 for $24 \mathrm{~h}$ with either $\alpha$-thrombin or TFLLR-NH ${ }_{2}$, the distribution of both myosin IIA and filamin B proteins shifted to being distributed throughout the cytoplasm to the membrane, with more intense luminescence signals than in the absence of stimulation. These results demonstrate that PAR1 activation induces cell morphological change associated with cell motility via Rho family activation and cytoskeletal protein overexpression, and has a critical role in gastric cancer cell invasion and metastasis.
\end{abstract}

Correspondence to: Dr Yasuo Hirono, First Department of Surgery, Faculty of Medicine, University of Fukui, 23-3 Matsuoka Shimoaiduki, Eiheiji-cho, Yoshida-gun, Fukui 910-1193, Japan

E-mail: hirono@u-fukui.ac.jp

Key words: proteinase-activated receptor-1, cellular morphology, myosin IIA, filamin B

\section{Introduction}

Tumor invasion and metastasis are the major causes of cancer deaths. Elucidation of the mechanisms underlying the metastatic spread of malignant cells leading to the invasion of distant tissues is a central goal in oncology (1). Metastatic progression is the result of a sequence of selective events that often involve interaction with elements of the tumor microenvironment $(2,3)$ and it is important to identify the specific cellular and biochemical mechanisms that confer increased metastatic capacity under these conditions. There is increasing evidence that the acidic component of the tumor microenvironment is an important determinant in controlling self-organized growth, invasive capacity, angiogenesis and subsequent malignant progression $(4,5)$. Modulation of tumor cell-substrate adhesion plays a crucial role in cellular processes such as migration, spreading, or contraction. These morphological changes are a result of the coordinated reorganization of the actin cytoskeleton induced by intra- or extra-cellular stimuli (6). Cell migration is sustained by the continuous growth of actin filaments at the leading edge, and the controlled retraction of adhesive contacts at the rear of the cell $(7,8)$.

A dysregulation of the coagulation cascade in the setting of human tumors has been recognized for over a century (9). In particular, active thrombin has been found to play an important role in terms of tumor behavior, affecting a variety of cancer-related processes including invasion and metastasis $(10,11)$. In large part, thrombin causes its cellular effects by cleaving and activating a novel set of proteinase-activated receptors (PARs 1 and 4; but not PAR2), that are members of the G-protein-coupled receptor (GPCR) superfamily (12-15). Although able to activate PARs 1 and 4, thrombin is not able to activate PAR2, which is a target for trypsin (16). Presently, we know that PAR1 is expressed in a variety of cell types. Moreover, PAR1 promotes transformation and tumor cell invasion and metastasis (11). Thrombin, the strongest activator of PAR1, functions as a potent mesenchymal cell mitogen and chemoattractant, promoting the recruitment and proliferation of mesenchymal cells at sites of injury and in tumors $(17,18)$. However, thrombin is not the only proteinase that activates 
PAR1. Recent studies revealed several other proteinases, including matrix metalloproteinase-1 (MMP-1) that can also activate PAR1. MMP-1 is commonly present in the tumor microenvironment, induces the expression of proinflammatory and proangiogenic genes and promotes tumor cell migration and invasiveness (19). PAR1 has been found to be instrumental in cell growth and invasion of tumor-derived cells $(20,21)$.

The Rho family of GTPases, including RhoA, Rac1 and $\mathrm{Cdc} 42$, has been implicated in the control of a wide range of biological process, such as the regulation of cytoskeletal structures, adhesion and motility which in turn permit invasion into the fibroblast monolayer in response to receptor stimulation $(22,23)$. Thrombin has been shown to stimulate signaling pathways that promote the activation of Rho family members (24). GPCRs transform cells through stimulation of signaling pathways that are regulated by members of the Rho family of small GTPases (25). Rho family proteins constitute a large subfamily of Ras-related GTPases whose activity is required for many aspects of cellular behavior $(22,25)$. First, Rho family proteins have been shown to have an important role in regulating the actin cytoskeletal organization. For example, Cdc42 stimulates the appearance of filopodia, Racl is a component of the signaling pathway leading to lamellipodia formation and membrane ruffling and RhoA regulates the formation of actin stress fibers and local adhesion $(23,26,27)$. Thus, we think that PAR1 may be involved in morphological changes in gastric cancer cells that facilitate invasion of healthy tissue.

In our previous studies, using an immunohistochemical approach with gastric carcinoma tissue, we found that the expression of PAR1, along with a metalloproteinase known to activate PAR1 (MMP1) were associated with poorer prognosis, compared with expression-negative tumors, and activated PAR1 promotes gastric cancer cell invasion and proliferation in vivo (28). In the present study, we employed gastric cancerderived cells that usually present a round morphology and in which PAR1 was not expressed. These cells were transfected with a PAR1 cDNA expressing plasmid so as to facilitate the expression of the PAR1 receptor protein and we evaluated the impact of PAR1 activation upon the invasion potential of the transfected cells. The effects on transformed MKN45/PAR1 cells and PAR1 null cells (MKN45) of the PAR1 agonists, thrombin and TFLLR- $\mathrm{NH}_{2}$ as well as the PAR1-inhibiting peptide SCH79797 were examined with respect to cytoskeletal morphological dynamics, quantities of cytoskeletal proteins and Rho-family activation dynamics as a function of time after PAR1 activation.

\section{Materials and methods}

Reagents. The monoclonal antibody against PAR1 (clone WEDE15) was purchased from Beckman Coulter (Fullerton, CA, USA). Anti-non-muscle myosin IIA was from GeneTex. Anti-filamin B was purchased from Chemicon. Human $\alpha$-thrombin was purchased from Sigma-Aldrich (catalog no. T1063) (St. Louis, MO, USA). The selective PAR1 antagonist SCH79797 (catalog no. 1592) $\left(\mathrm{IC}_{50}=70 \mathrm{nM}\right)$ and PAR1 agonist TFLLR-NH $\mathrm{N}_{2}$ (catalog no. 1464) were purchased from Tocris Bioscience (Anonmouth, UK) (29).
Cell culture. The human gastric cancer MKN45 and MKN74 cells were obtained from the Riken Cell Bank. Cells were cultured at $37^{\circ} \mathrm{C}$ in $5 \% \mathrm{CO}_{2}$ in RPMI-1640 medium containing $10 \%$ fetal bovine serum (FBS). Cells were propagated by mechanical re-suspension using a scraper, without the use of trypsin. PAR1 is expressed in MKN74, not in MKN45 (28).

Establishment of PARl-expressing MKN45 stable cell line. PAR1-expressing MKN45 stable cell line was established as previously reported (28). Briefly, MKN45 cells were transfected using Lipofectamine 2000 (Invitrogen) and pcDNA3.1-PAR1 (MKN45/PAR1) or pcDNA3.1-empty-vector alone (for MKN45/mock as the control). Individual G418 resistant $(0.75 \mathrm{mg} / \mathrm{ml})$ clones were picked and analyzed for PAR1 expression by RT-PCR and immunoblotting of total cell extract.

Western blot analysis. Total protein was extracted from the cultured cells using RIPA buffer (PBS containing 1\% NP-40, $0.1 \%$ sodium deoxycholate, $0.1 \%$ SDS and $10 \mu \mathrm{g} / \mathrm{ml}$ leupeptin, $10 \mu \mathrm{g} / \mathrm{ml}$ aprotinin, $1 \mathrm{mM}$ phenylmethlsulfonyl fluride). Proteins in the lysate were resolved by SDS-PAGE mode of a linear gradient gel using a 5-20\% SuperSep gel (Wako, Osaka, Japan) and resolved proteins were transferred by semi-dry blotting apparatus to nitrocellulose or PVDF membrane. After the electrophoretic transfer (Bio-Rad, Hercules, CA), the membrane was blocked in $3 \%$ non-fat dry milk TBS containing $0.1 \%$ Tween-20 and incubated with primary antibody overnight at $4^{\circ} \mathrm{C}$. An enhanced chemiluminescence detection system (ECL-Plus, GE Healthcare, Buckinghamshire, UK) was used for visualization of immunoreactive-bands after the reaction with the HRP-labeled secondary antibody against mouse or rabbit IgG.

SDS-PAGE and Coomassie Blue staining. A sample protein was resolved by means of SDS-PAGE under reducing condition for $60 \mathrm{~min}$ with a constant voltage of $200 \mathrm{~V}$. The gel was fixed in $7 \% \mathrm{CH}_{3} \mathrm{COOH}, 50 \% \mathrm{C}_{2} \mathrm{H}_{5} \mathrm{OH}$ for $20 \mathrm{~min}$ and washed three times in ultra-pure water. After staining the gel with Bio-Safe Coomassie (Bio-Rad) for $30 \mathrm{~min}$ the gel was destained with three successive changes of ultra-pure water.

In-gel protein digestion. The protein bands of interest were excised and further diced into $1-\mathrm{mm}^{3}$ pieces. Gel pieces were destained by soaking with several changes of $50 \%$ acetonitrile and proteins were then reduced with $25 \mathrm{mM}$ DTT and alkylated with $100 \mathrm{mM}$ iodoacetamide. Trypsin $(10 \mathrm{ng} / \mu \mathrm{l})$ in $10 \mu \mathrm{l}$ of $50 \mathrm{mM} \mathrm{NH}_{4} \mathrm{HCO}_{3}$ was added to the gel pieces and 'in-gel' digestion was done overnight at $37^{\circ} \mathrm{C}$. Peptides were extracted three times in $50 \mu$ l of TEA (1\%)/50\% AcCN. Pooled extract was dried using a Speed-Vac. Peptides were resuspended and purified by a ZipTip (Millipore). Prior to MALDI-TOF/MS analysis, peptides were dried and dissolved into $50 \% \mathrm{AcCN} / 0.1 \%$ TFA.

MALDI-TOF/MS analysis. Peptide mass fingerprinting (PMF) analysis was performed using an Autoflex MALDI-TOF mass spectrometer (Bruker Daltonics). The sample was spotted on an AnchorChip target (Bruker Daltonics) with $1 \mu \mathrm{l}$ of freshly prepared HCCP (2-hydroxy-2-cyanocinnamic acid) 


\section{MKN45/PAR1}

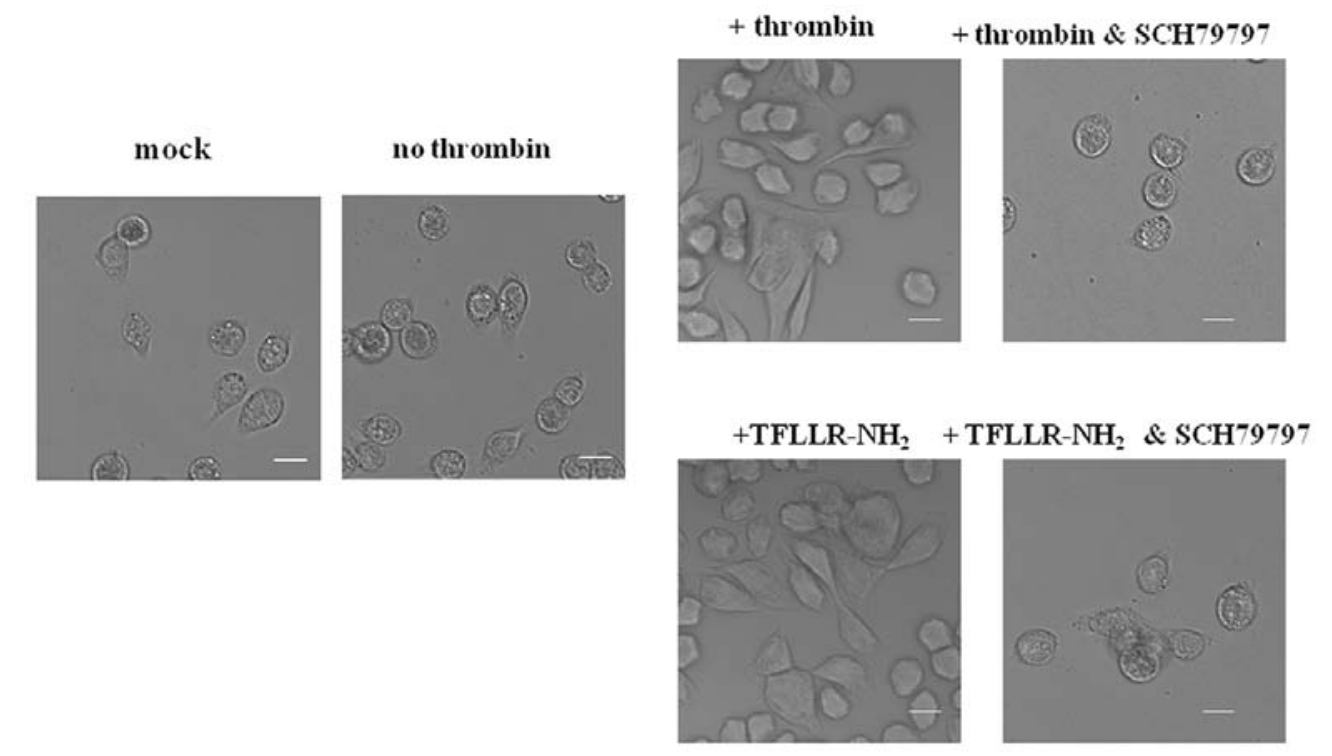

Figure 1. PAR1 activation caused changes in the morphology. Gastric cancer MKN45 cells were epithelial-like round shape originally. MKN45/mock and MKN45/PAR1 were also epithelial-like in their quiescent states. On the other hand, MKN45/PAR1, which were treated with $15 \mathrm{nM} \alpha$-thrombin or $30 \mu \mathrm{M}$ TFLLR- $\mathrm{NH}_{2}$ for $24 \mathrm{~h}$, elicited dramatic morphological change to flattened and extended irregular shapes distinctly different from original shape. MKN45/PAR1 did not change the shape, with addition of either $\alpha$-thrombin or TFLLR- $\mathrm{NH}_{2}$ and $70 \mathrm{nM} \mathrm{SCH79797.} \mathrm{Scale} \mathrm{bar,} 10 \mu \mathrm{m}$.

matrix solution of 2,5-dihydroxybezoic acid (DHB) (Bruker Daltonics). Mass was estimated as \pm 0.15 Da. Peptide masses were acquired for a range of ca. $\mathrm{m} / \mathrm{z} 800$ to 4,000 .

Database analysis. Searches for PMF were performed using the NCBInr and Swiss-Prot databases using Mascot PMF database search software. The oxidation of methionine and the alkylation of cysteine were included as a possible modification. The mass tolerance for the monoisotopic peptide masses was set to $\pm 0.15 \mathrm{Da}$.

GTP-bound RhoA and Racl pull-down assay. MKN45/mock cells were treated with $15 \mathrm{nM} \alpha$-thrombin for $5 \mathrm{~min}, 6$ and $12 \mathrm{~h}$ under a condition of serum starvation. MKN45/PAR1 cells were treated with $15 \mathrm{nM} \alpha$-thrombin for $1,3,5,10$, $30 \mathrm{~min}, 1,3,6$ and $12 \mathrm{~h}$. Cells from each culture were lysed and lysates were separately incubated with Rhotekin-RBD beads and PAK-RBD beads for $1 \mathrm{~h}$ by rotating the contents at $4^{\circ} \mathrm{C}$. The beads were washed and GTP-bound and total levels of RhoA and Racl proteins were detected by immunoblotting, using respective monoclonal antibodies against RhoA or Rac1 (1:500; Cytoskeleton).

Immunofluorescence. Cultured cells were fixed with $4 \%$ paraformaldehyde at room temperature, permeabilized with $0.1 \%$ Triton $\mathrm{X}-100$ in PBS and blocked with $3 \%$ FBS in PBS. Following overnight incubation at $4^{\circ} \mathrm{C}$ with primary antibodies, and incubation in the dark with Alexa 405 and 488 Fluor dye-labeled secondary antibodies (anti-mouse and anti-goat), immunofluorescence was detected using a Leica DMLB confocal laser fluorescence microscope (Leica Microsystems).

\section{Results}

PARl activation caused changes in the morphology of receptor-expressing gastric cancer cells. MKN45 cells grow with epithelial-like round shape morphology. However, we observed that upon stimulation with $\alpha$-thrombin (15 nM, $24 \mathrm{~h}$ ) or TFLLR-NH $\mathrm{N}_{2}(30 \mu \mathrm{M}, 24 \mathrm{~h}) \mathrm{MKN} 45 / \mathrm{PAR} 1$ grow with an elongated and polarized morphology, extending pseudopodia at the leading edge (Fig. 1). MKN45/PAR1 did not show any changes in cell shape upon addition of $\alpha$-thrombin or TFLLR-NH ${ }_{2}$ in the presence of $70 \mathrm{nM} \mathrm{SCH79797,} \mathrm{indicating}$ that morphological change was mediated by PAR1 activation (Fig. 1). We also found that the same morphological change in MKN74 was mediated by $\alpha$-thrombin or TFLLR-NH ${ }_{2}$, and MKN74 did not show any changes in the presence of SCH79797 (Fig. 2).

a-thrombin induces RhoA and Racl activation in PARl-transfected cells. Given the shape changes caused by $\alpha$-thrombin activation of PAR1, we hypothesized that activation of the small G-proteins, RhoA and Rac1, known to be involved in cytoskeletal modulation, might be involved. To test this hypothesis, using a GST-RBD fusion protein pull-down assay, we evaluated $\alpha$-thrombin-triggered RhoA/Racl activation in MKN45/PAR1. The gross quantity of RhoA and Rac1 proteins were found to be somewhat similar for MKN45/PAR1 cultured both with and without $\alpha$-thrombin as indicated by immunoreactive bands of similar intensity presented by means of immuno-blotting (Figs. 3 and 4). In MKN45/PAR1, RhoA was rapidly activated (RhoA-GTP) within $1 \mathrm{~min}$ of PAR1 stimulation with $\alpha$-thrombin and declined to near base line within $30 \mathrm{~min}$, but the activity of RhoA was enhanced again 


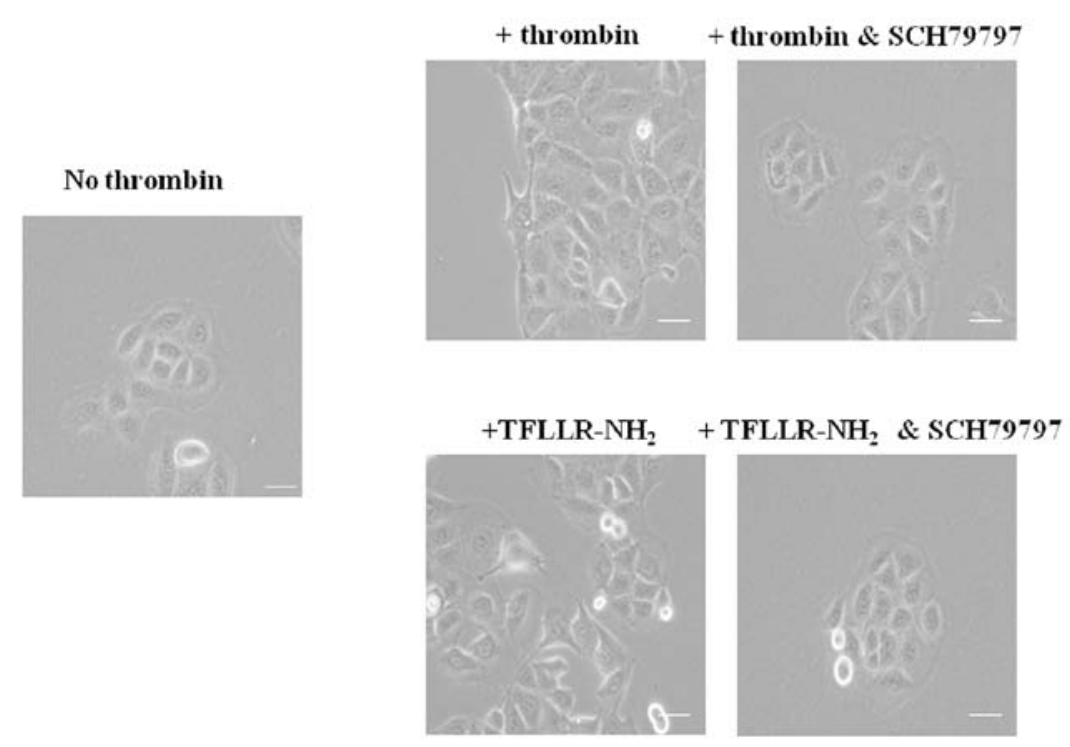

Figure 2. MKN74, which expressed PAR1, showed morphological change. When gastric cancer MKN74 cells were treated with $15 \mathrm{nM} \alpha$-thrombin or $30 \mu \mathrm{M}$ TFLLR-NH $\mathrm{N}_{2}$ for $24 \mathrm{~h}$, it was elicited morphological change to flattened and extended irregular shapes distinctly different form original shape. When SCH79797 was added, morphological change was not observed. Scale bar, $10 \mu \mathrm{m}$.

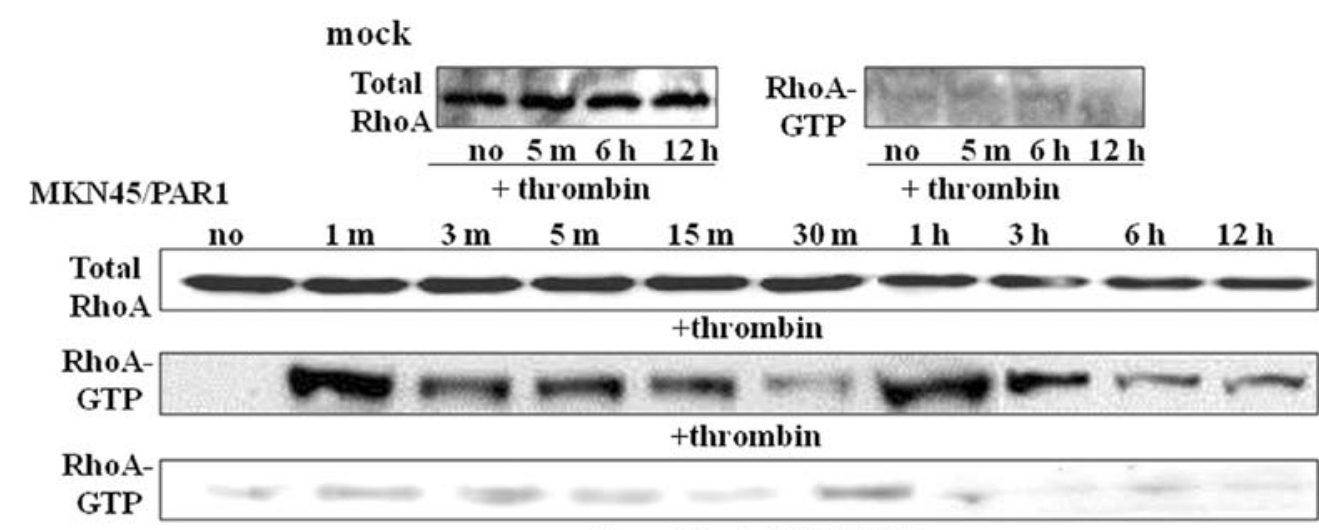

+ thrombin \& SCH79797

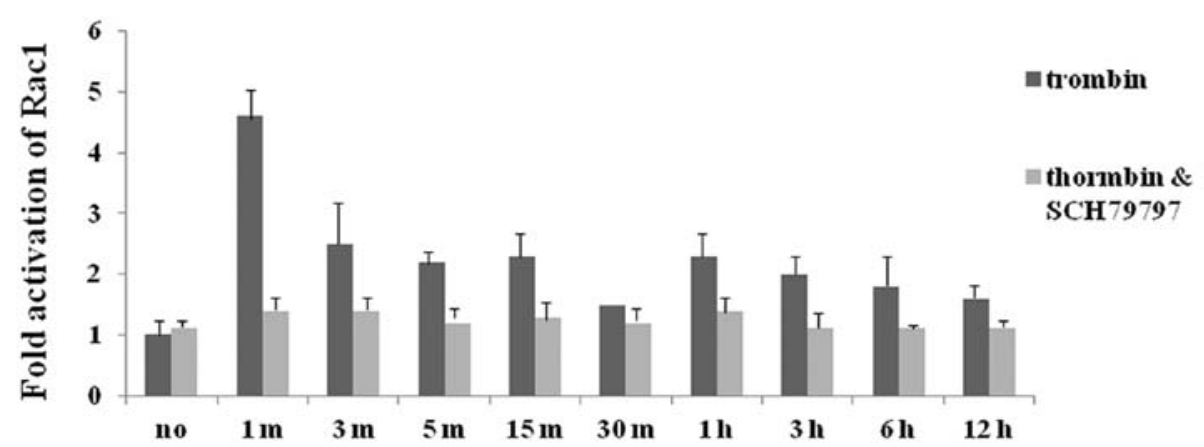

Figure 3. The change in the quantity of GTP-RhoA by $\alpha$-thrombin. Western blot analyses and immunolabelling were carried out upon activated-RhoA (GTPRhoA) pull-down assays and total RhoA directly from lysates of various cultures of MKN45/PAR1 cells as well as MKN45/mock cells in order to quantify the impact of $15 \mathrm{nM} \alpha$-thrombin stimulation upon the level of RhoA and activated RhoA in these cultures over various periods of time. MKN45/mock cells were cultured both in the absence of $\alpha$-thrombin and in the presence of $15 \mathrm{nM} \alpha$-thrombin for periods of $5 \mathrm{~min}, 6$ and $12 \mathrm{~h}$. MKN45/PAR1 cells were cultured in the presence of $15 \mathrm{nM} \alpha$-thrombin for the periods of 1,3,5, 15,30 min, 1, 3, 6 and $12 \mathrm{~h}$ and other cultures of MKN45/PAR1 cells were carried out in the presence of $15 \mathrm{nM} \alpha$-thrombin and $70 \mathrm{nM} \mathrm{SCH79797} \mathrm{for} \mathrm{same} \mathrm{periods.} \mathrm{Subsequent} \mathrm{densitometric} \mathrm{analysis} \mathrm{of} \mathrm{RhoA} \mathrm{levels} \mathrm{was} \mathrm{carried} \mathrm{out} \mathrm{upon} \mathrm{MKN45/PAR1}$ cell cultures and resultant total RhoA levels (RhoA and activated RhoA) were derived from the luminosity presented by immunolabelling of the western blot analysis of the cultures. Total RhoA levels were expressed as multiples of the luminosity presented by total RhoA from MKN45/PAR1 cells cultured in the absence of $\alpha$-thrombin (bottom). Data are expressed as mean values \pm SD from triplicate experiments. 

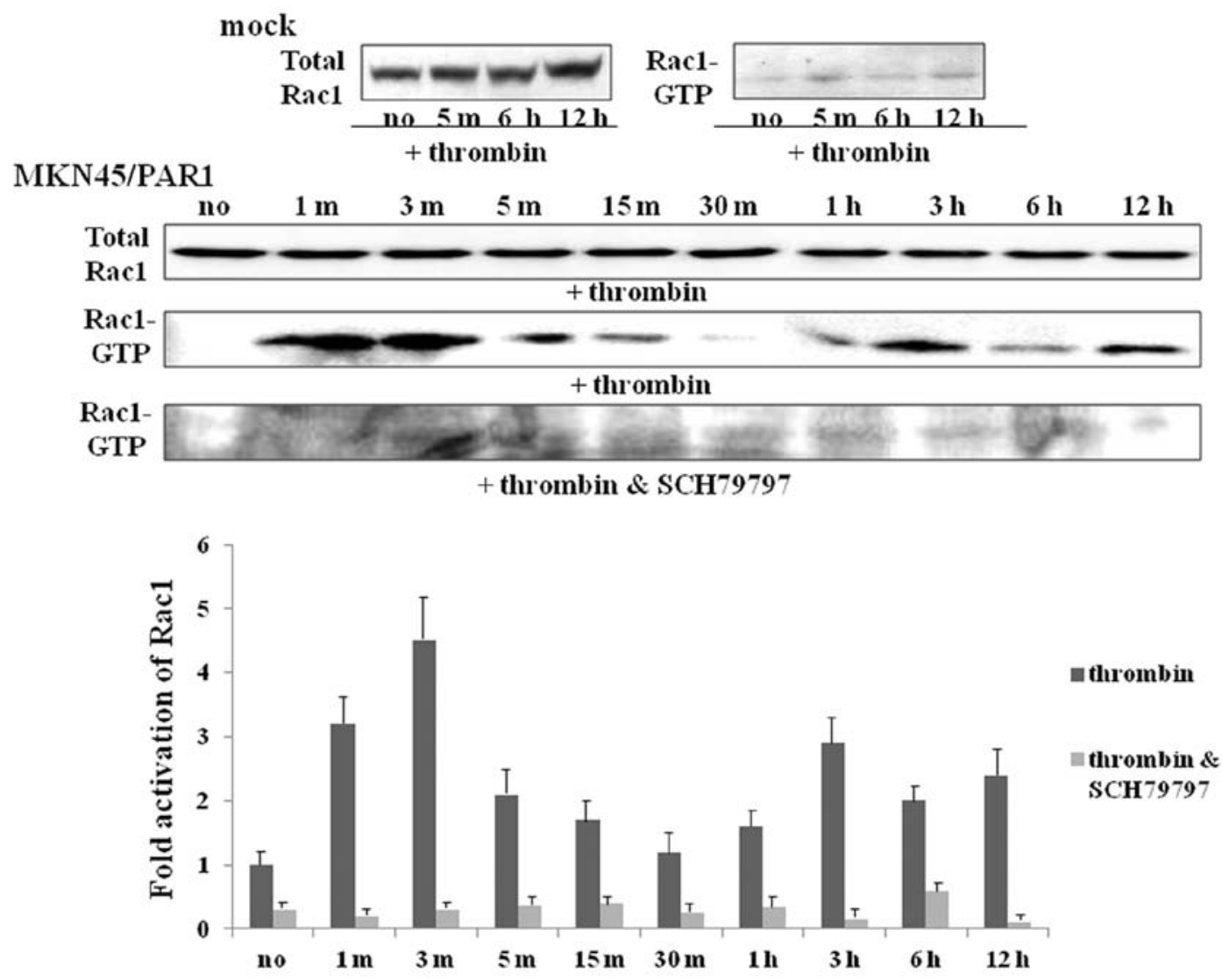

Figure 4. The change in the quantity of GTP-Rac1 by $\alpha$-thrombin. Western blot analyses and immunolabeling were carried out upon activated-Rac1 (GTP-Rac1) pull-down assays as well as total Rac1 (Rac1 and activated-Rac1) directly from lysates of various cultures of MKN45/PAR1 cells as well as MKN45/mock cells in order to quantify the impact of $\alpha$-thrombin stimulation upon the level of Rac1 and activated-Racl in these cultures over various periods of time. MKN45/mock cells were cultured both in the absence of $\alpha$-thrombin and in the presence of $15 \mathrm{nM} \alpha$-thrombin for periods of $5 \mathrm{~min}, 6$ and $12 \mathrm{~h}$. MKN45/PAR1 cells were cultured in the presence of $15 \mathrm{nM} \alpha$-thrombin for periods of 1, 3, 5, 15,30 min, 1, 3,6 and $12 \mathrm{~h}$ and other cultures of MKN45/PAR1 cells were carried out in the presence of $15 \mathrm{nM} \alpha$-thrombin and $70 \mathrm{nM}$ SCH79797 for the same periods. Subsequent densitometric analysis of Rac1 levels was carried out upon MKN45/PAR1 cell cultures and resultant total Racl levels (Racl and activated Rac1) were derived from the luminosity presented by immunolabeling of the western blot analysis of the cultures. Total Rac1 levels were expressed as multiples of the luminosity presented by total Rac1 from MKN45/PAR1 cells cultured in the absence of $\alpha$-thrombin (bottom). Data are expressed as mean values \pm SD from triplicate experiments.

and maintained till at least $12 \mathrm{~h}$ after initial activation (Fig. 3). Similarly, $\alpha$-thrombin treatment-indicated Rac1 activation arose within 1 min and then declined, but was enhanced again. A faint trace of Racl activation was apparent one hour after $\alpha$-thrombin stimulation and slight increase in Racl activation was observed $6 \mathrm{~h}$ after $\alpha$-thrombin stimulation with greater levels of activated Racl apparent $12 \mathrm{~h}$ after stimulation relative to cultures of MKN45/PAR1 not exposed to $\alpha$-thrombin (Fig. 4). Activation of both RhoA and Racl was found to be greatly inhibited in MKN45/PAR1 cultured with both the PAR1 stimulant $\alpha$-thrombin and PAR1 antagonist SCH79797 (Figs. 3 and 4).

Overexpression and location of myosin IIA and filamin B in relation to the formation of stress-fibers. SDS-PAGE analysis of lysates of MKN45/PAR1 and MKN45/mock separately cultured in the absence of $\alpha$-thrombin presented no bands in the molecular mass region greater than $200 \mathrm{kDa}$ upon staining with Coomassie Blue while lysates of MKN45/PAR1 cultured in the presence of $\alpha$-thrombin presented bands in this region above $200 \mathrm{kDa}$ (Fig. 5A). The proteins in these bands were identified as myosin IIA (lower region) and filamin B (upper region) by MASCOT searches using PMF data obtained from and Autoflex MALDI-TOF/MS analyzer. The identity of both of these proteins was verified by means of immunoblotting employing antibodies specific to each protein (Fig. 5B). Subsequent immuno-fluorescence visualization of myosin IIA and filamin B in MKN45/PAR1 cultured under five distinct conditions which include the absence of stimulants, stimulated for $24 \mathrm{~h}$ by $15 \mu \mathrm{M} \alpha$-thrombin, stimulated by $30 \mu \mathrm{M}$ TFLLR-NH $\mathrm{N}_{2}$, stimulated for $24 \mathrm{~h}$ by $15 \mu \mathrm{M} \alpha$-thrombin in the presence of $70 \mathrm{nM} \mathrm{SCH79797} \mathrm{and} \mathrm{stimulated} \mathrm{by} 30 \mu \mathrm{M}$ TFLLR-NH $\mathrm{N}_{2}$ in the presence of $70 \mathrm{nM} \mathrm{SCH79797.} \mathrm{When}$ MKN45/PAR1 cells were cultured in the absence of stimulants expression of myosin IIA and filamin B was detected in low abundance localized near the interior of the plasma membrane. Stimulation of MKN45/PAR1 for $24 \mathrm{~h}$ with either $\alpha$-thrombin or TFLLR-NH $\mathrm{N}_{2}$ resulted in myosin IIA and filamin B proteins presenting stronger signals localized throughout the cytoplasm and increasing in intensity up to the plasma membrane. Immuno-fluorescence of MKN45/PAR 1 cultured for $24 \mathrm{~h}$ in the presence $\alpha$-thrombin and SCH79797 indicates that 
A

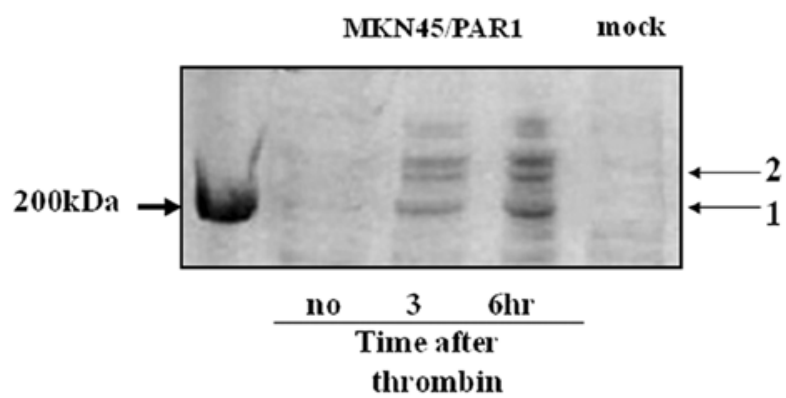

\begin{tabular}{ccccccccc}
$\begin{array}{c}\text { Spot } \\
\text { no }\end{array}$ & proteinAC & AC name & $\begin{array}{c}\text { Size } \\
\text { (Da) }\end{array}$ & pI & $\begin{array}{c}\text { Mascot } \\
\text { score }\end{array}$ & $\begin{array}{c}\text { Coverage } \\
(\%)\end{array}$ & $\begin{array}{c}\text { matched } \\
\text { /unmatched }\end{array}$ & common name \\
\hline 1 & Q258K2 & MYH9 & 227646 & 5.50 & 168 & 21 & $31 / 24$ & $\begin{array}{c}\text { myosin-heavychain } \\
\text { nonmuscle IIA }\end{array}$ \\
2 & O75369 & Flnb & 278875 & 5.46 & 86 & 8 & $13 / 8$ & filamin B \\
\hline
\end{tabular}

B

mock

MKN45/PAR1

Myosin IIA

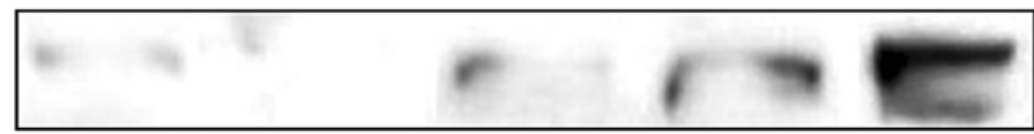

Filamin B

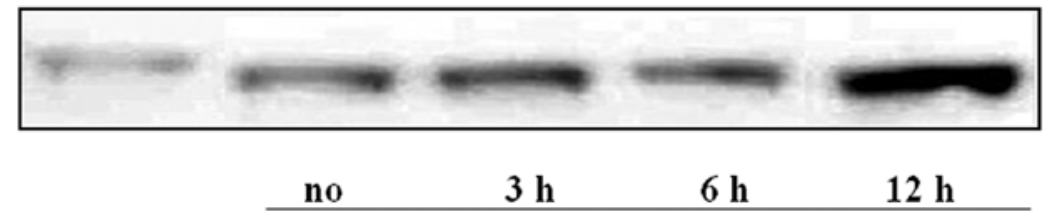

+ thrombin

Figure 5. Myosin IIA and filamin B identified by MALDI-TOF/MS and western blot analysis. (A) SDS-PAGE CBB staining of the whole cell extracts from MKN45/mock and MKN45/PAR1 activated with $15 \mathrm{nM} \alpha$-thrombin. The whole cell extracts from MKN45/mock (far right lane), MKN45/PAR1 not stimulated by $\alpha$-thrombin (2nd lane from the left) and MKN45/PAR1 treated with $15 \mathrm{nM} \alpha$-thrombin for 3 (3rd lane from the left) and $6 \mathrm{~h}$ (4th lane from the left) were resolved on SDS-PAGE and the gel was stained with CBB. Area above $200 \mathrm{kDa}$ was enlarged to permit precise cutting of protein bands, 1 and 2 (labeled far right), which are absent from the lysates from MKN45/mock and inactivated MKN45/PAR1. The differentially expressed bands were excised, in-gel-digested and subjected to MALDI-TOF analysis. Proteins were identified by Mascot search of PMF data and are annotated. The bottom table is a summary of the Mascot search results in considerably high Mascot T scores and matching rates identified two proteins, the myosin-heavy chain non-muscle IIA and filamin B. (B) Western blot analysis was carried out upon whole cell extracts of MKN45/mock cultured in the absence of $\alpha$-thrombin and MKN45/PAR1 cultured in the presence of $15 \mathrm{nM} \alpha$-thrombin for 3, 6 and $12 \mathrm{~h}$ (the dilutions of myosin IIA and filamin B antibodies were 1:500). Subsequent MALDI-TOF/ MS analysis of bands localized during western blot analysis confirmed the presence of myosin IIA and filamin B.

SCH79797 attenuated the impact $\alpha$-thrombin stimulation had upon the expression and redistribution of myosin IIA and filamin B (Fig. 6).

\section{Discussion}

The successive steps involved in cell migration include extension of the leading process, followed by translocation of the soma and retraction of the trailing process. These events require the coordinated activity of various intracellular signaling mechanisms. During migration, the growth cone of the leading process senses guidance cues present in the extracellular environment. These cues, acting through appropriate receptors on the growth cone, induce changes in the concentration of calcium ions, both in the growth cone and in the soma. These changes in the distribution of calcium ions cause a redistribution of intracellular Rho family proteins and the eventual translocation of the soma. The trailing process is retracted as the cell moves forward.

The purpose of this study was to determine whether or not thrombin, through PAR1 activation, influences the process of gastric cancer cell morphological change which in turn facilitates cell migration. We have identified a cDNA derived from the NUGC3 gastric cancer cell line that is strongly transforming when expressed in MKN45 cells. This cDNA was identified as a gene encoding the full-length, wild-type thrombin receptor PAR1 (28). A PAR1 oncoprotein function is consistent with a role for thrombin in the regulation of cell proliferation in fibroblasts and other cell types $(30,31)$. In addition to its focus-forming 


\section{Anti-Myosin IIA (blue)/Anti-Filamin B (green)}

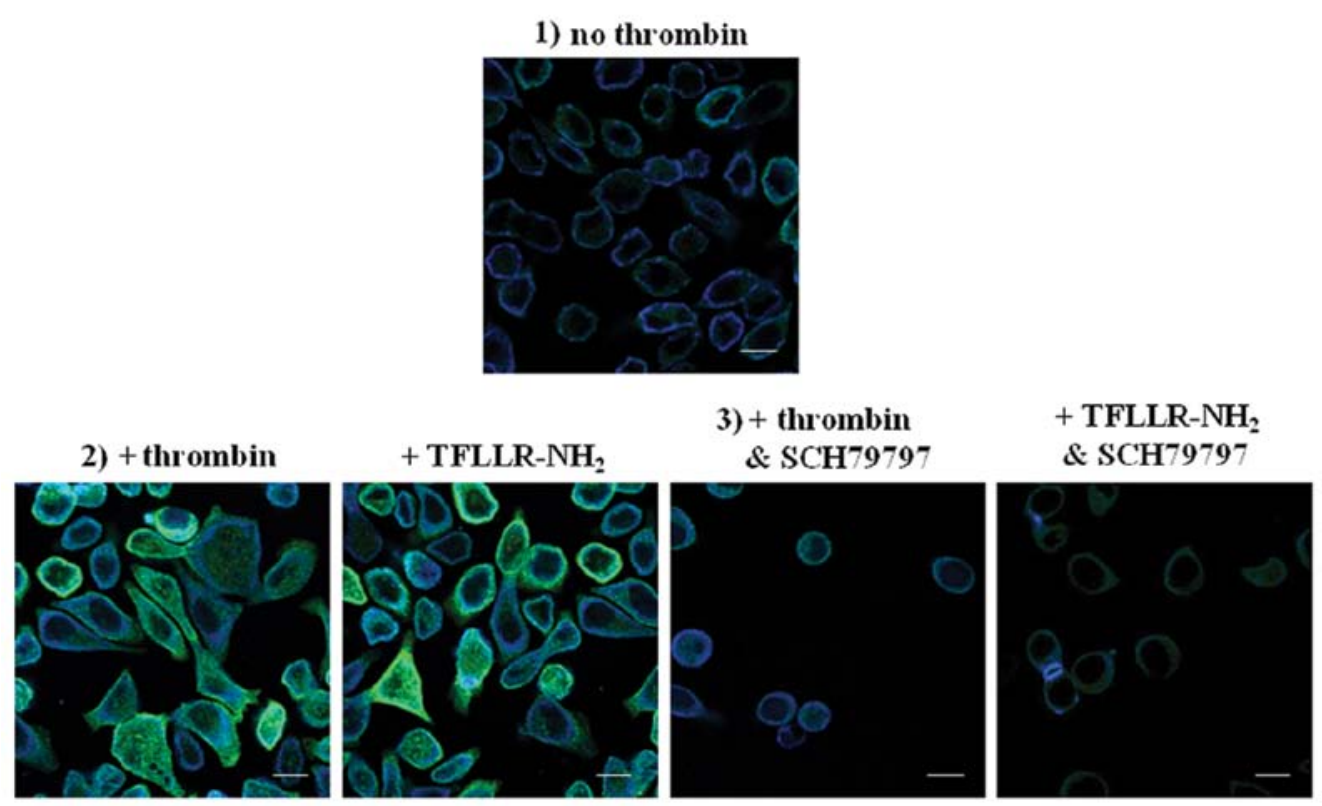

Figure 6. Confocal imaging for fluorescence immuno-staining of myosin IIA and filamin B. Immuno-fluorescence visualization of the distribution of myosin IIA and filamin B in MKN45/PAR1 cells cultured under five distinct conditions which include: i) cultured in the absence of PAR1 stimulation by $\alpha$-thrombin in which low amounts of myosin IIA and filamin B were distributed at or near the inner surface of the plasma membrane; ii) stimulated for $24 \mathrm{~h}$ by $15 \mathrm{nM} \alpha$-thrombin in which apparently much higher levels of mysoin IIA and filamin B were distributed in greatest density at or near the plasma membrane and decreasing in density towards the interior of the cell; iii) stimulated by $30 \mu \mathrm{M}$ TFLLR-NH2 in which much higher levels of myosin IIA and filamin B were again apparent and again were distributed in greatest density at or near the plasma membrane and decreasing in density towards the interior of the cell; iv) stimulated for $24 \mathrm{~h}$ by $15 \mathrm{nM} \alpha$-thrombin in the presence of $70 \mathrm{nM} \mathrm{SCH79797} \mathrm{in} \mathrm{which} \mathrm{low} \mathrm{amounts} \mathrm{of} \mathrm{myosin} \mathrm{IIA} \mathrm{and} \mathrm{filamin} \mathrm{B} \mathrm{were} \mathrm{distributed} \mathrm{at} \mathrm{or} \mathrm{near} \mathrm{the} \mathrm{plasma} \mathrm{membrane;} \mathrm{and} \mathrm{v)} \mathrm{stimulated} \mathrm{by} 30 \mu \mathrm{M}$ TFLLR-NH2 in the presence of $70 \mathrm{nM}$ SCH79797 in which low amounts of myosin IIA and filamin B were again distributed at or near the plasma membrane. Myosin IIA was immune-stained with a secondary antibody labeled with the Alexa fluor 405-labeled mouse IgG (blue) and filamin B with a secondary antibody labeled with the Alexa fluor 488-labeled mouse IgG (green). Scale bar, $10 \mu \mathrm{m}$.

activity, stable expression of the PAR1 cDNA in MKN45 cells promoted growth and invasion in low serum condition (28).

Thrombin stimulation has been shown to stimulate signaling pathways that promote the activation of proteins that are members of the Rho family (32). The activation of GPCRs has been linked to the activation of proteins that are members of the Rho family $(33,34)$. Members of Rho family proteins have been shown to play an important role in regulating actin cytoskeletal organization. RhoA regulates the formation of actin stress fibers and focal adhesions, and Racl causes lamellipodia formation and membrane ruffling. Lamellipodium is a characteristic feature at the leading edge and is believed to be the actual motor and steering device that maneuvers cells during migration. Cells initiate migration by extending their plasma membrane in the form of lamellipodia that requires the re-orchestration of the cell cytoskeleton (6). Our proteomics and western blot analysis indicates increased expression of myosin IIA and filamin B was present in $\alpha$-thrombin stimulated PAR1/MKN45 relative to mock and non-stimulated PAR1/MKN45. Both myosin IIA and filamin B are constituents of actin microfilament-based cytoskeleton. PAR1/MKN45 stimulated with $\alpha$-thrombin $15 \mathrm{nM}$ for $24 \mathrm{~h}$ presented a higher abundance of myosin IIA and filamin B relative to controls with the greatest densities of the proteins evident along the interior surface of the cell membrane in the form of lamellipodia. Myosin II is a hexameric molecule comprised of a pair of heavy chains, essential light chains, and a pair of regulatory light chains (35). The three myosin IIs, known as myosin IIA, IIB and IIC, are distinguished by their unique heavy chain isoforms. Interestingly, each isoform performs the same basic molecular function, which is the binding and contraction of F-actin in an ATP-dependent manner, and the activities of all three are thought to be regulated in a similar fashion; that is, through phosphorylation of the regulatory light chains (35). The forces that are generated by contraction of the actin-myosin cytoskeleton contribute to cell migration (36). Myosin IIA protein is involved in determining the fate of the extension of lamellipodia by means of distinct, but linked roles in the regulation of focal contact formation and actin network reorganization (37). Myosin IIA also acts with myosin-interacting guanine nucleotide exchange factor to regulate the polarity and invasion activity of breast cancer cells through activation of RhoA (38). The filamin family consists of three paralogues (filamin A, B and C). Filamins are able to cross-link with the actin cytoskeleton forming orthogonal networks which in turn modulate cell shape changes and cell motility (39). They are involved in the organization of the cytoskeleton and appear to be necessary for cell adhesion and motility $(40,41)$. Filamin B has been shown to interact with many proteins. These interactions, such as with transmembrane receptors and signaling molecules, result in great functional diversity $(42,43)$. Filamin B homodimers probably regulate the actin cytoskeleton through interactions derived from its multiple receptor binding regions, thereby regulating cell capability, protrusion and migration. 
Loss of filamin A or filamin B has little effect on migration but knockout of filamin A and filamin B impairs migration, and the observed defect is primarily due to a deficiency in the initiation of motility (44). Filamin B plays an essential role in the basic processes of cell migration.

We found that the RhoA and Rac1 pull-down assays indicated that the increase in the activated forms of RhoA and Rac1 occurred within 1 min after $\alpha$-thrombin stimulation and continued for at least $12 \mathrm{~h}$, although declined once within 30 min. SCH79797, an antagonist of PAR1, inhibited RhoA and Rac1 activation. These data indicated that PAR1 activation increased RhoA and Racl activation. These long-term actions of $\alpha$-thrombin, in contrast with the effects of PAR-activating peptides may be mediated by receptors and mechanisms other than those encompassing PAR1 (45). Thus, although we also have showed that RhoA and Racl initially triggered activation by PAR1 within $1 \mathrm{~min}$, the sustained responses very likely mediated by 'feed-forward' mechanisms, for example involving the production of autocrine stimulatory factors like the one(s) detected in the concentrated cell supernatants and/or the sequential and synergistic cooperation of several transcription factors. We showed that activation of PAR1 phospholyrated NF- $\mathrm{KB}$ and epidermal growth factor receptor (EGFR) for a period of up to $12 \mathrm{~h}$ and tenascin-C (TN-C), which is overexpressed by PAR1 activation, and is possibly associated with EGFR activations (28). Rho family activation, including RhoA and Rac1, was dependent on signaling from EGFR $(46,47)$. We think that activation forms of RhoA and Rac1 in early-phase response within 1 min after $\alpha$-thrombin addition are mediated by activated PAR1 signaling pathway and activation forms of RhoA and Racl in the late-phase response $1 \mathrm{~h}$ after $\alpha$-thrombin addition are mediated by $\mathrm{TN}-\mathrm{C} /$ EGFR signaling pathway, following PAR1 activation and TN-C overexpression. Furthermore, we observed that MKN45/ PAR1 cells presented alterations in cell morphology after thrombin or PAR1 agonist stimulation and such cytoskeletal rearrangements were not found when SCH79797 was present. Cleavage of PAR1 by thrombin stimulates Gqa which promotes phospholipase $\mathrm{C}$ activity, catalyzing production of inositol-1,4,5-trisphophate, and increases in intracellular $\mathrm{Ca}^{2+}(48)$. The $\mathrm{Ca}^{2+}$ release associated with PAR1 activation has been shown to enhance myosin light chain (MLC) kinase activity, resulting in increased MLC phosphorylation and the interaction of myosin with actin filaments to form stress fibers $(49,50)$. Additionally, stimulation of PAR1 initiates RhoA/Rho kinase signaling through activation of G12/13 $\alpha$ or possibly via Gq $\alpha$-mediated induction of Rho guanine nucleotide exchange factors $(51,52)$. These events also contribute to the redistribution of filamentous actin and augment stress fiber formation and membrane retraction $(53,54)$.

Migrating cells extend protrusions with broad lamellipodia at the front, which are driven by actin polymerization and are stabilized by adhering to the extracellular matrix. Members of the Rho family of small GTPases are key regulators of the actin cytoskeleton in diverse cellular functions including cell migration. In particular, a Rho family GTPase known as Rac1 is activated at the leading edge of motile cells and induces the formation of actin-rich lamellipodia protrusions, which serve as a major driving force of cell movement $(55,56)$. The major downstream protein targets for Racl that mediate actin polymerization in lamellipodia protrusions are WAVE family proteins, the activators of the Arp $2 / 3$ complex $(57,58)$. Activated Arp2/3 complex induces rapid polymerization of actin and the formation of the branched actin filaments present in lamellipodia $(59,60)$. In keeping with the promotion of cell invasion as a result of PAR1 activation (28), we have found here that inhibition of PAR1 activation by SCH79797 reduces cell invasion. Activation of Racl and formation of lamellipodia at the leading edge is attenuated by SCH79797. Thus, PAR1 is a key upstream regulator for Rac1 during cell cytoskeletal dynamics.

Cell invasion is facilitated by the acquisition of motility which in turn is made possible through multiple-gene activation steps involving several lines of functional genes and regulation of signaling proteins, along with activated gene end-products. Our findings underline the pivotal role of PAR1 activation in tumor invasion and metastasis. Furthermore, our results support the hypothesis that PAR1 antagonists are effective anti-invasion and anti-metastasis agents and as such have potential therapeutic applications in gastric cancer treatment. Further elucidation of mechanisms underlying thrombin-induced migration, and invasion processes in PAR1/MKN45 may hold promise for new therapeutic strategies.

\section{Acknowledgements}

This study was supported in part by Grant-in-Aid 14770636 for Scientific Research from the Ministry of Education, Culture, Sports, Science and Technology, Japan (to Y.H.).

\section{References}

1. Kurschat $P$ and Mauch C: Mechanisms of metastasis. Clin Exp Dermatol 25: 482-489, 2000.

2. Rofstad EK: Microenviroment-induced cancer metastasis. Int J Radiat Biol 76: 589-605, 2000.

3. Bhujwalla ZM, Artemov D, Ballesteros P, Cerdan S, Gillies RJ, et al: Combined vascular and extracellular $\mathrm{pH}$ imaging of solid tumors. NMR Biomed 15: 114-119, 2002.

4. Gatenby RA and Gawlinski ET: Mathematical models of tumour invasion mediated by transformation-induced alteration of microenvironmental pH. Novartis Found Symp 240: 85-96, 2001.

5. Xu L, Fukumura D and Jain RK: Acidic extracellular $\mathrm{pH}$ induces vascular endothelial growth factor (VEGF) in human glioblastoma cells via ERK1/2 MAPK signaling pathway: mechanism of low pH-induced VEGF. J Biol Chem 277: 11368-11374, 2002.

6. Lauffenburger DA and Horwitz AF: Cell migration: a physically integrated molecular process. Cell 84: 359-369, 1996.

7. Horwitz AR and Parsons JT: Cell migration - movin' on. Science 286: 1102-1103, 1999.

8. Ballestrem C, Wehrle-Haller B, Hinz B and Imhof BA: Actin-dependent lamellipodia formation and microtubuledependent tail retraction control-directed cell migration. Mol Biol Cell 11: 2999-3012, 2000.

9. Prins $\mathrm{M}$ and Otten HMM: Thrombosis and cancer. A short history of Trousseau's syndrome. In: Thrombosis and Cancer. Lugassy G, Falanga A, Kakkar A and Rickles F (eds). Taylor \& Francis, London, pp1-10, 2004.

10. Walz DA and Fenton JW: The role of thrombin in tumor cell metastasis. Invasion Metastasis 14: 303-308, 1994.

11. Nierodzik ML and Karpatkin S: Thrombin induces tumor growth, metastasis, and angiogenesis: Evidence for a thrombinregulated dormant tumor phenotype. Cancer Cell 10: 355-362, 2006.

12. Coughlin SR: Protease-activated receptors in hemostasis, thrombosis and vascular biology. J Thromb Haemost 3: 1800-1814, 2005.

13. Hollenberg MD and Compton SJ: International Union of Pharmacology. XXVIII. Proteinase-activated receptors. Pharmacol Rev 54: 203-217, 2002. 
14. Steinhoff M, Buddenkotte $\mathrm{J}$ and Shpacovitch V, et al: Proteinase-activated receptors: transducers of proteinasemediated signalong in inflamation and immune response. Endocr Rev 26: 1-43, 2005.

15. Ramachandran $\mathrm{R}$ and Hollenberg MD: Proteinases and signaling: pathophysiological and therapeutic implications via PARs and more. Br J Pharmacol 153 (Suppl 1): S263-S282, 2008.

16. Nystedt S, Emilsson K, Wahlestedt C and Sundelin J: Molecular cloning of a potential proteinase activated receptor. Proc Nat Acad Sci USA 91: 9208-9212, 1994.

17. Chambers RC, Dabbagh K, McAnulty RJ, Gray AJ, BlancBrude OP and Laurent GJ: Thrombin stimulates fibroblast procollagen production via proteolytic activation of proteaseactivated receptor 1. Biochem J 333: 121-127, 1998

18. Dawes KE, Gray AJ and Laurent GJ: Thrombin stimulates fibroblast chemotaxis and replication. Eur J Cell Biol 61: 126-130, 1993

19. Boire A, Covic L, Agarwal A, Jacques S, Sherifi S and Kuliopulos A: PAR1 is a matrix metalloproteinase-1 receptor that promotes invasion and tumorigenesis of breast cancer cells. Cell 120: 303-313, 2005.

20. Even-Ram SC, Uziely B, Cohen P, Grisaru-Granovsky S, Maoz M, et al: Thrombin receptor overexpression in malignan and physiological invasion processes. Nat Med 4: 909-914, 1998.

21. Even-Ram SC, Maoz M and Pokroy E: Tumor cell invasion is promoted by activation of protease activated receptor- 1 in cooperation with the alpha beta 5 integrin. J Biol Chem 276 : 10952-10962, 2001.

22. Van Aelst L and D'Souza-Schorey C: Rho GTPases and signaling networks. Genes Dev 11: 2295-2322, 1997.

23. Nobes CD and Hall A: Rho, rac, and cdc42 GTPases regulate the assembly of multimolecular focal complexes associated with actin stress fibers, lamellipodia, and filopodia. Cell 81: 53-62, 1995.

24. Seasholtz TM, Majumdar M, Kaplan DD and Brown JH: Rho and Rho kinase mediate thrombin-stimulated vascular smooth muscle cell DNA synthesis and migration. Circ Res 84 1186-1193, 1999.

25. Zohn IE, Symons M, Chrzanowska-Wodnicka M, Westwick JK and Der CJ: Mas oncogene signaling and transformation require the small GTP-binding protein Rac. Mol Cell Biol 18 : 1225-1235, 1998.

26. Ridley AJ and Hall A: The small GTP-binding protein rho regulates the assembly of focal adhesions and actin stress fibers in response to growth factors. Cell 70: 389-399, 1992.

27. Ridley AJ, Paterson HF, Johnston CL, Diekmann D and Hall A: The small GTP-binding protein rac regulates growth factorinduced membrane ruffling. Cell 70: 401-410, 1992.

28. Fujimoto D, Hirono Y, Goi T, Katayama K, Matsukawa S and Yamaguchi A: The activation of proteinase-activated receptor-1 (PAR1) mediates gastric cancer cell proliferation and invasion. BMC Cancer 10: 443, 2010

29. Ahn HS, Foster C, Boykow G, Stamford A, Manna M and Graziano M: Inhibition of cellular action of thrombin by N3-cyclopropyl-7-[[4-(1-methylethyl)phenyl]methyl]7 H-pyrrolo[3, 2-f]quinazoline-1,3-diamine (SCH79797), a nonpeptide thrombin receptor antagonist. Biochem Pharmacol 60: $1425-1434,2000$

30. Dery O, Corvera CU, Steinhoff M and Bunnett NW: Proteinaseactivated receptors: novel mechanisms of signaling by serine proteases. Am J Physiol Cell Physiol 274: C1429-C1452, 1998.

31. Van Obberghen-Schilling E, Vouret-Craviari V, Chen $\mathrm{YH}$, Grall D, Chambard JC and Pouyssegur J: Thrombin and its receptor in growth control. Ann NY Acad Sci 766: 431-441, 1995.

32. Seasholtz TM, Majumdar M and Brown JH: Rho as a mediator of $\mathrm{G}$ protein-coupled receptor signaling. Mol Pharmacol 55 949-956, 1999.

33. Kozasa T, Jiang X, Hart MJ, et al: p115 RhoGEF, a GTPase activating protein for Galpha12 and Galpha13. Science 280 2109-2111, 1998

34. Hart MJ, Jiang X, Kozasa T, et al: Direct stimulation of the guanine nucleotide exchange activity of p115 RhoGEF by Galpha13. Science 280: 2112-2114, 1998.

35. Bresnick AR: Mechanisms of nonmuscle myosin-II regulation. Curr Opin Cell Biol 11: 26-33, 1999.
36. Warrick HM and Spudich JA: Myosin structure and function in cell motility. Annu Rev Cell Biol 3: 379-421, 1987.

37. Giannone G, Dubin-Thaler BJ, Rossier O, et al: Lamellipodial actin mechanically links myosin activity with adhesion-site formation. Cell 128: 561-575, 2007.

38. Wu D, Asiedu M and Wei Q: Myosin-interacting guanine exchange factor (MyoGEF) regulates the invasion activity of MDA-MB-231 breast cancer cells through activation of RhoA and RhoC. Oncogene 28: 2219-2230, 2009.

39. Robertson SP: Filamin A: phenotypic diversity. Curr Opin Genet Dev 15: 301-307, 2005.

40. Weihing RR: The filamins: properties and functions. Can J Biochem Cell Biol 63: 397-413, 1985.

41. Cunningham CC: Actin structural proteins in cell motility. Cancer Metastasis Rev 11: 69-77, 1992.

42. Takafuta T, Saeki M, Fujimoto TT, Fujimura K and Shapiro SS A new member of the LIM protein family binds to filamin B and localizes at stress fibers. J Biol Chem 278: 12175-12181, 2003.

43. van der Flier A, Kuikman I, Kramer D, et al: Different splice variants of filamin-B affect myogenesis, subcellular distribution, and determine binding to integrin [beta] subunits. J Cell Biol 156: 361-376, 2002.

44. Baldassarre M, Razinia Z, Burande CF, Lamsoul I, Lutz PG and Calderwood DA: Filamins regulate cell spreading and initiation of cell migration. PLoS One 4: e7830, 2009.

45. Hollenberg M.D, Mokashi M, Leblond L and DiMaio J: Synergistic actions of a thrombin-derived synthetic peptide and a thrombin receptor-activating peptide in stimulating fibroblast mitogenesis. J Cell Physiol 169: 491-496, 1996.

46. Badgwell DB, Lu Z, Le K, et al: The tumor-suppressor gene ARHI (DIRAS3) suppresses ovarian cancer cell migration through inhibition of Stat3 and FAK/Rho signaling pathway. Oncogene 31: 68-79, 2012

47. Betson M, Lozano E, Zhang J and Braga VM: Rac activation upon cell-cell contact formation is dependent on signaling from the epidermal growth factor receptor. J Biol Chem 277: 36962-36969, 2002

48. Macfarlane SR, Seatter MJ, Kanke T, Hunter GD and Plevin R: Proteinase-activated receptors. Pharmacol Rev 53: 245-282, 2001.

49. Bogatcheva NV, Garcia JG and Verin AD: Molecular mechanisms of thrombin-induced endothelial cell permeability. Biochemistry (Mosc) 67: 75-84, 2002.

50. Garcia JG, Pavalko FM and Patterson CE: Regulation of endothelial cell gap formation and barrier dysfunction: role of myosin light chain phosphorylation. J Cell Physiol 163: 510-522, 1995.

51. Buhl AM, Johnson NL, Dhanasekaran N and Johnson GL: $\mathrm{G}$ alpha 12 and $\mathrm{G}$ alpha 13 stimulate Rho-dependent stress fiber formation and focal adhesion assembly. J Biol Chem 270: 24631-24634, 1995.

52. Majumdar M, Seasholtz TM, Buckmaster C, Toksoz D and Brown JH: A rho exchange factor mediates thrombin and $\mathrm{G} \alpha(12)$-induced cytoskeletal responses. J Biol Chem 274: 26815-26821, 1999.

53. Amano M, Ito $\mathrm{M}$ and Kimura $\mathrm{K}$, et al: Phosphorylation and activation of myosin by Rho-associated kinase (Rho-kinase). J Biol Chem 271: 20246-20249, 1996.

54. Kimura K, Ito M, Amano M, et al: Regulation of myosin phosphatase by Rho-associated kinase (Rho-kinase). Science 273: 245-248, 1996.

55. Kraynov VS, Chamberlain C, Bokoch GM, Achwartz MA, Slabough S and Hahn KM: Localized Rac activation dynamics visualized in living cells. Science 290: 333-337, 2000.

56. Small JV, Stradal T, Vignal E and Rottner K: The lamellipodium: where motility begins. Trends Cell Biol 12: 112-120, 2002.

57. Miki H, Suetsugu S and Takenawa T: WAVE, a novel WASP-family protein involved in actin reorganization induced by Rac. EMBO J 17: 6932-6941, 1998.

58. Yamazaki D, Suetsugu S, Miki H, et al: WAVE2 is required for directed cell migration and cardiovascular development. Nature 424: 452-456, 2003

59. Welch MD and Mullins RD: Cellular control of actin nucleation. Annu Rev Cell Dev Biol 18: 247-288, 2002.

60. Pollard TD and Borisy GG: Cellular motility driven by assembly and disassembly of actin filaments. Cell 112: 453-465, 2003. 